\title{
THE RELATIONSHIP BETWEEN GENOTYPE AND REPRODUCTIVE PERFORMANCE BEFORE PARTURITION IN MICE*
}

\author{
D. P. BOSHIER $\uparrow$ \\ Biology Department, Brown University, Providence, R.I., U.S.A.
}

(Received 17th April 1967)

\begin{abstract}
Summary. Reproductive performance before parturition has been investigated in laboratory mice of two breeding systems, each of two highly inbred strains and their $F_{1}$ progeny. More corpora lutea of pregnancy were found in the BUB and I/Fn strains than in the C57BL/10J and $A / F n$ strains respectively, or in the $F_{1} s$ derived from the pairs contrasted.

BUB and I/Fn females had more pre-implantation and fewer postimplantation losses than females of the $\mathrm{C} 57 \mathrm{BL} / 10 \mathrm{~J}$ and $\mathrm{A} / \mathrm{Fn}$ strains, while $F_{1}$ females lost proportionately fewest potential young both before and after implantation. The number of conceptuses lost at different times during pregnancy differed proportionately in the populations examined and the BUB females differed from all others in not having a marked rise in embryonic mortality at about the 10th day of gestation. The significance of this departure from the norm is discussed.
\end{abstract}

\section{INTRODUCTION}

The number of progeny born to polytocous mammals is a function of the number of good ova produced by the female, the efficiency of fertilization, the compatibility of the progeny and the dam within the uterine environment and the embryonic genotype. However, potential fertility frequently exceeds actual fertility. The difference as Parkes (1923) and other investigators have shown (see McLaren, 1963), is primarily a reflection of embryonic or foetal mortality resulting from genetic or environmental factors.

This paper reports detailed investigations, in four strains of highly inbred mice and two $F_{1}$ s derived from them, of three factors important in prenatal reproductive performance in mature female mice, namely, the numbers of corpora lutea of pregnancy present considered as indicating the numbers of ova shed (Bowman \& Roberts, 1958), the numbers of post-ovulation embryonic losses and the times during gestation at which embryonic death occurred.

* Based on data presented in a thesis submitted in partial fulfilment of the requirements for the Ph.D. degree, Brown University.

$\dagger$ U.S.P.H.S. Predoctoral Trainee and Fulbright Travel Grantee. Supported by Grants CRT 5007, 2G-329, partly by Grant C-592 to Herman B. Chase, Brown University. Present address: Department of Physiology and Anatomy, Massey University, Palmerston North, New Zealand. 


\section{MATERIALS AND METHODS}

Inbred mice of the A/Fn, BUB, C57BL/10J and I/Fn strains were used. They were kept in breeding units of two, three or four virgin females (normally 6 to 8 weeks old) per male, and were housed under standard conditions in two breeding systems:

1. BUB $0 \times \mathrm{BUB}$ 우우

C57BL $\delta \times$ G57BL $q 9$

$\mathrm{F}_{1} \delta \times \mathrm{F}_{1}$ 우, where the $\mathrm{F}_{1} \mathrm{~s}$ were the progeny of both crosses of the BUB and C57BL strains;

2. $\mathrm{A} / \mathrm{Fn} \sigma^{x} \times \mathrm{A} / \mathrm{Fn}$ 우우 I/Fn $\delta \times \mathbf{I} / \mathbf{F n}$ 우

$F_{1} \delta \times F_{1}$ 우, where the $F_{1}$ s were the progeny of both crosses of the A/Fn and I/Fn strains.

Each $F_{1}$ group was designated to show its relationship to the female parent, namely:

BUB $0 \times$ C57BL $q$ gave $F_{1}$ progeny which were designated the $\mathrm{Fc}$ breeding population;

C57BL $0 \times \mathrm{BUB}$ o gave $\mathrm{F}_{1}$ progeny which were designated the $\mathrm{Fb}$ breeding population.

Similarly, $\mathrm{Fa}$ and $\mathrm{Fi}$ designate animals derived from $\mathrm{A} / \mathrm{Fn}$ and $\mathrm{I} / \mathrm{Fn}$ females respectively.

The females were examined each morning and the presence of copulation plugs taken as evidence of mating (Day 0). At specified later dates which gave a series of gestation periods between 7 days and term, the females were killed by ether inhalation, and the numbers of corpora lutea, implantation sites and viable or non-viable embryos or foetuses were counted on each side of the reproductive tract. Early in the study, the products of pregnancies of known length were compared with the pre-natal stages described by Grüneberg (1943) and in no case was there a difference of more than half a day in development. This allowed the length of gestations, where no copulation plug had been seen, and the time at which developmental arrest had occurred in dead embryos, to be estimated.

\section{RESULTS}

\section{Corpora lutea counts}

In the pregnant females which were examined at various times between the 7th and 18th day of gestation, there was a difference of only three in the mean number of corpora lutea per mouse between the most fertile (BUB), and the least fertile $(\mathrm{A} / \mathrm{Fn})$ strains (Table 1$)$. In both breeding systems, the $\mathrm{F}_{1}$ s produced about the same number of corpora lutea as did the less fertile parent. Thus neither $\mathbf{F}_{1}$ population had as many corpora lutea as did its more fertile parent, despite other heterotic effects observed (see below).

As also shown in Table 1, a statistically significant negative correlation existed between the numbers of corpora lutea present in right and left ovaries in all the breeding populations, i.e. if either ovary had more than half the mean 
TABLE 1

GOMPARISONS BETWEEN AND WITHIN INBRED STRAINS AND THEIR $F_{1}$ S OF OVARIAN PERFORMANCE AS MEASURED BY THE NUMBER OF CORPORA LUTEA IN RIGHT AND LEFT OVARIES IN PREGNANT FEMALES

\begin{tabular}{|c|c|c|c|c|c|c|}
\hline & \multicolumn{6}{|c|}{ Breeding populations } \\
\hline & $B U B$ & $F b+F c^{1}$ & $C 57 B L$ & $I$ & $F i+F a^{1}$ & $A$ \\
\hline $\begin{array}{l}\text { No. females examined } \\
\text { Total No. corpora lutea } \\
\text { Mean No. corpora lutea } \\
\text { Variance ratio }\end{array}$ & $\begin{array}{c}56 \\
728 \\
13 \cdot 0 \pm 0 \cdot 34 \\
F=18 \cdot 85\end{array}$ & $\begin{array}{c}36 \\
402 \\
11 \cdot 2 \pm 0 \cdot 21 \\
\text { d.f. }=2141\end{array}$ & $\begin{array}{c}52 \\
560 \\
10 \cdot 8 \pm 0 \cdot 24 \\
1 ; P<0 \cdot 01\end{array}$ & $\begin{array}{c}43 \\
546 \\
12 \cdot 7 \pm 0 \cdot 45 \\
F=20 \cdot 85\end{array}$ & $\begin{array}{c}52 \\
521 \\
10 \cdot 0 \pm 0 \cdot 22 \\
\text { d.f. }=2120\end{array}$ & $\begin{array}{c}28 \\
283 \\
10 \cdot 1 \pm 0 \cdot 32 \\
0 ; P<0 \cdot 01\end{array}$ \\
\hline Ranked means comparisons ${ }^{3}$ & $B U$ & $B>F_{1}>C 57$ & $B L$ & & $I>A>F_{1}$ & \\
\hline $\begin{array}{l}\text { Mean No. CL in } R \text { ovary } \\
\text { Mean No. CL in L ovary }\end{array}$ & $\begin{array}{l}6 \cdot 3 \pm 0 \cdot 28 \\
6 \cdot 7 \pm 0 \cdot 27\end{array}$ & $\begin{array}{l}5 \cdot 3 \pm 0 \cdot 25 \\
6 \cdot 0 \pm 0 \cdot 23\end{array}$ & $\begin{array}{l}5 \cdot 7 \pm 0 \cdot 19 \\
5 \cdot 1 \pm 0 \cdot 19\end{array}$ & $\begin{array}{l}6 \cdot 5 \pm 0.25 \\
6 \cdot 2 \pm 0.26\end{array}$ & $\begin{array}{l}4 \cdot 6 \pm 0.25 \\
5 \cdot 4 \pm 0.27\end{array}$ & $\begin{array}{l}4 \cdot 8 \pm 0 \cdot 30 \\
5 \cdot 3 \pm 0 \cdot 29\end{array}$ \\
\hline $\begin{array}{l}\text { Comparison of } R \text { and } L \\
\text { ovaries by } t \text {-test }\end{array}$ & 1.03 & $2 \cdot 06^{*}$ & $2 \cdot 23^{*}$ & 0.83 & $2 \cdot 17^{*}$ & 1.58 \\
\hline $\begin{array}{l}\text { Correlation between } R \text { and } \\
\text { L ovaries }\end{array}$ & $-0 \cdot 28^{*}$ & $-0 \cdot 62 * *$ & $-0.83^{*}$ & $-0.34^{*}$ & $-0 \cdot 66^{* *}$ & $-0.40^{*}$ \\
\hline
\end{tabular}

${ }^{1} F_{1}$ data pooled, no statistically significant differences between populations present.

2 Mean \pm S.E. of mean.

3 After using Kramer's (1956) Range Test $(P<0 \cdot 01)$.

4 Symbols used throughout this paper: $0.05>P>0.01$; ** $0.01>P>0.001$; *** $P<0.001$; n.s. = not significant.

number of corpora lutea, then the other ovary tended to have fewer than the mean by about the same number. This negative correlation had no relationship between sides in three of the six populations examined. In both $F_{1} s$ the left ovary produced more corpora lutea than did the right, whereas in the C57BL strain the right ovary was dominant. When the differences between the numbers of corpora lutea present in the right and left ovaries were considered further in the inbred strains in which there was no unilateral ovarian dominance, the data demonstrated that in the three breeding populations those differences varied about the binomial distribution, but statistically significant departures from it did not occur (Table 2).

Numbers and significance of intra-uterine losses

Data obtained after direct examination of the uterine contents of the pregnant females demonstrated that both $F_{1}$ populations were the most efficient breeders, for between eight and nine of every ten eggs produced had persisted

TABLE 2

SIGNIFICANCE OF DEPARTURES FROM BINOMIAL DISTRIBUTION OF NUMBERS OF GORPORA LUTEA IN RIGHT AND LEFT OVARIES

\begin{tabular}{l|c|c|c|c|c}
\hline \multicolumn{1}{c|}{ Strain } & $\frac{\varepsilon d^{2}}{\varepsilon n}$ & $\frac{H^{*}}{\left(\times 10^{4}\right)}$ & $\frac{S . E . \text { of } H}{\left(\times 10^{4}\right)}$ & $\frac{H}{S . E . ~ o f H}$ & $\mathbf{P}$ \\
\hline BUB & 0.85 & -28.25 & 36.17 & -0.08 & n.s. \\
A & 0.32 & -92.31 & 68.63 & -1.35 & n.s. \\
I & 0.74 & -53.28 & 40.80 & -1.31 & n.s. \\
\hline
\end{tabular}

" 'Heterogeneity' as determined by Falconer et al. (1961). 
TABLE 3

PATTERNS OF EMBRYONIC MORTALITY BETWEEN OVULATION AND END OF GESTATION AS SHOWN BY NUMBERS OF INTRA-UTERINE DEATHS IN BREEDING POPULATIONS EXAMINED

\begin{tabular}{|c|c|c|c|c|c|c|}
\hline & $B U B$ & $F b+F c$ & $C 57 B L$ & $I$ & $F_{i}+F_{a}$ & $A$ \\
\hline $\begin{array}{l}\text { No. of females examined } \\
\text { No. of females pregnant } \\
\text { No. of corpora lutea }{ }^{1} \\
\text { No. of implants } \\
\text { Loss pre-implantation }\end{array}$ & \begin{tabular}{lr}
\multicolumn{2}{c}{75} \\
59 \\
396 & 371 \\
286 & 318 \\
110 & 63
\end{tabular} & \begin{tabular}{rr}
\multicolumn{2}{c}{42} \\
42 \\
254 & 221 \\
225 & 186 \\
29 & 35
\end{tabular} & \begin{tabular}{rr}
\multicolumn{2}{c}{79} \\
60 \\
309 & 340 \\
255 & 289 \\
54 & 51
\end{tabular} & \begin{tabular}{rr}
\multicolumn{2}{c}{63} \\
48 \\
296 & 312 \\
212 & 233 \\
84 & 79
\end{tabular} & \begin{tabular}{rr}
\multicolumn{2}{c}{54} \\
54 \\
292 & 249 \\
262 & 223 \\
30 & 26
\end{tabular} & \begin{tabular}{rr}
\multicolumn{2}{c}{52} \\
28 \\
148 & 135 \\
123 & 104 \\
25 & 31
\end{tabular} \\
\hline $\begin{array}{l}\text { No. of dead embryos } \\
\text { Days } 5 \text { to } 7 \\
\text { Days } 8 \text { to } 11 \\
\text { Days } 12 \text { to term } \\
\text { No. of pregnancies in } \\
\text { which all potential } \\
\text { embryos were viable } \\
\text { No. of pregnancies in } \\
\text { which all embryos died } \\
\text { before or after im- } \\
\text { plantation }\end{array}$ & $\begin{array}{ll}6 & 6 \\
(12) & \\
7 & 5 \\
(17) & \\
3 & 1 \\
(30) & \end{array}$ & $\begin{array}{ll}1 & 0 \\
8^{(1)} & 8 \\
2^{(5)} & 1 \\
(36) & \end{array}$ & $\begin{array}{cc}6^{6} & 3 \\
19^{(6)} & 35 \\
5_{(7)} & \\
5_{(47)} & 5\end{array}$ & $\begin{array}{ll}15 & 7 \\
& \\
23^{(4)} & 25 \\
\cdot(10) & \\
0 & 3 \\
(34) & \end{array}$ & $\begin{array}{ll}4 & 1 \\
5^{(4)} & 5 \\
3^{(5)} & 0 \\
(45) & \end{array}$ & $\begin{array}{cc}7 & 4 \\
12 & 12 \\
12 & 12 \\
{ }^{(3)} & 2 \\
1_{(22)} & 2\end{array}$ \\
\hline
\end{tabular}

${ }^{1}$ Columns giving data for left and right sides of pregnant female reproductive tracts.

2 Number in parentheses refers to number of females examined at each stage. Each female may contribute to total embryonic mortality of prior stages.

as viable embryos (Table 3). The inbred populations were less efficient, with comparable figures ranging from $7 \frac{1}{2}$ in the BUB strain to $6 \frac{1}{2}$ in the $\mathrm{A} / \mathrm{Fn}$ strain. These differences were due to the fact that the $F_{1}$ s lost fewer potential young both before and after implantation than did their inbred parents. The inbred females of the BUB and I/Fn strains shed more eggs and had more pre-implantation, and fewer post-implantation, losses than did the C57BL and A/Fn strain females.

The six breeding populations had a similar pattern of prenatal mortality in that the pre-implantation losses were largest and were followed by a progressive decrease in the numbers of embryonic deaths. The post-implantation mortality, however, in all populations except the BUB group, increased between the 8th and 11th day of gestation and then rapidly returned to an almost negligible rate after the 12 th day (Text-fig. 1). In the C57BL population and its

TABLE 4

COMPARISONS OF THE NUMBERS OF EMBRYOS LOST WITHIN THE BREEDING POPULATIONS AND BETWEEN RIGHT AND LEFT SIDES OF THE REPRODUGTIVE TRAGT

\begin{tabular}{l|c|c|c|c|c|c}
\hline & $B U B$ & $F b+F c$ & $C 57 B L$ & $I$ & $F i+F a$ & $A$ \\
\hline$\chi^{2}$ & $3 \cdot 82$ & 0.95 & 0.46 & 0.36 & 0.30 & 0.42 \\
d.f. & 2 & 2 & 2 & 2 & 2 & 2 \\
$P$ & n.s. & n.s. & n.s. & n.s. & n.s. & n.s. \\
\hline
\end{tabular}




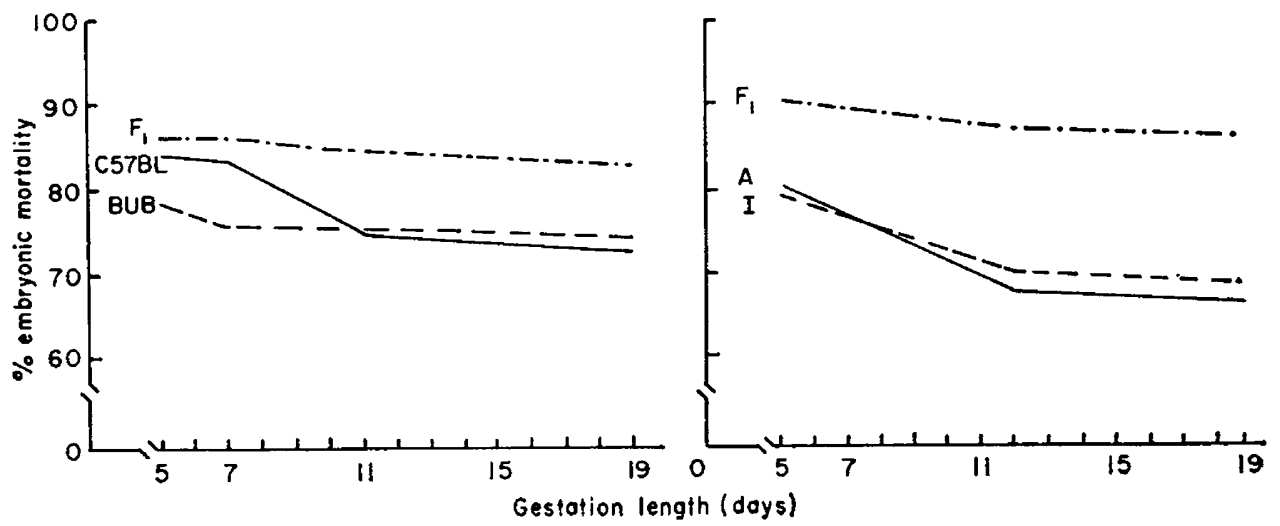

Text-rig. 1. Patterns of embryonic mortality during gestation in the populations examined. Data points at 5 days p.c., 7 days p.c., 12 days p.c. and term are calculated as follows:

$$
\frac{\text { Number of viable conceptuses }}{\text { Number of corpora lutea }} \%
$$

$\mathbf{F}_{1}\left(\mathrm{~F}_{2}\right.$ foetuses $)$ respectively, $30.3 \%$ and $19.0 \%$ of the total post-ovulation losses occurred during this period, in contrast with the $6 \%$ lost in BUB females. The higher death rates also present at this time in the $\mathrm{I} / \mathrm{Fn}$ and $\mathrm{A} / \mathrm{Fn}$ strains breeding system differed little between the three populations, although they were at a somewhat lower level in the $F_{1}$ group.

As has been shown above, the post-ovulation losses were in a similar pattern in all groups; yet differences between populations within either breeding system were present (Text-fig. 2). Within the BUB and C57BL breeding system, the variations (heterogeneity $\chi^{2}=61.83$, d.f. $=8, P<0.001$ ) were due to the

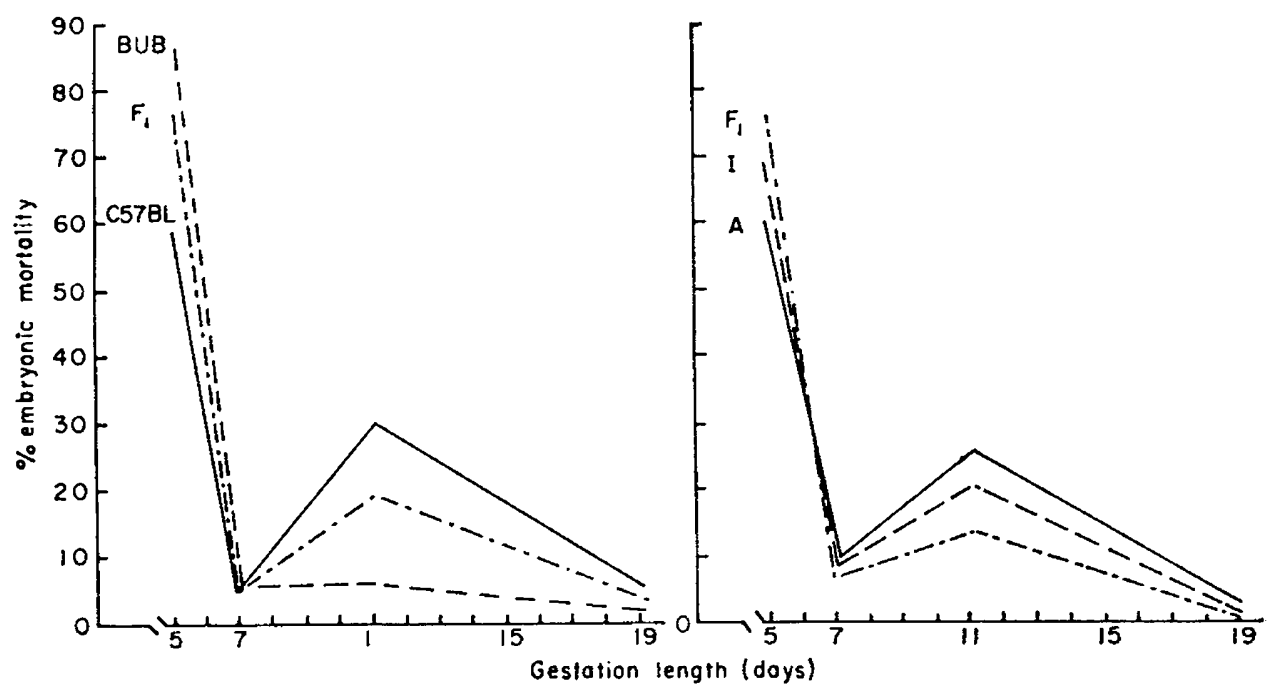

Text-Fig. 2. A comparison of the distributions of the embryonic mortality during pregnancy. Data points are calculated for each breeding population as follows:

$\frac{\text { Number of deaths at gestation length noted }}{\text { Total post-ovulation deaths }} \%$ 
high pre-implantation losses in the BUB females and the different patterns of post-implantation mortality characteristic of each strain. The BUB strain distribution of post-implantation embryonic mortality differed from both that of the C57BL strain $\left(\chi^{2}=8.36\right.$, d.f. $\left.=1, P<0.05\right)$ and that of the $F_{1}$ population $\left(\chi^{2}=31.41\right.$, d.f. $\left.=1, P<0.001\right)$ principally in its lack of increased embryonic death between the 8th and 11 th day of gestation. The C57BL and $F_{1}$ groups were similar $\left(\chi^{2}=0.30\right.$, d.f. $\left.=1, P>0.05\right)$.

Although comparable differences existed within the I/Fn and A/Fn strains breeding system (heterogeneity $\chi^{2}=55.67$, d.f. $=6, P<0.001$ ), these resulted primarily from the fact that the $F_{1}$ group had fewest losses both before and after implantation, leaving it with considerably more viable embryos than were present in either of the inbred parent populations. This difference was most marked between the $\mathrm{I} / \mathrm{Fn}$ and $\mathrm{F}_{1}$ females $\left(\chi^{2}=13.09\right.$, d.f. $\left.=6, P<0.05\right)$ and was also indicated when the $\mathrm{A} / \mathrm{Fn}$ strain was compared with the $\mathrm{F}_{1}$ population $\left(\chi^{2}=11 \cdot 10\right.$, d.f. $\left.=6, P=0.08\right)$. That the A/Fn and $\mathrm{I} / \mathrm{Fn}$ strains were similar in their patterns of post-ovulation losses was suggested by the data of Table 3 which were obtained from females in which implantations had occurred. However, of the total number of females examined after copulation plugs were seen, only $54 \%$ of the A/Fn strain females contained implanted embryos, compared with the $76 \%$ found in females of the $\mathrm{I} / \mathrm{Fn}$ strain. Therefore, in the A/Fn strain, inclusion of data from females in which implantation did not follow mating, demonstrated that its pattern of intra-uterine mortality was, in fact, different from that of the I strain because of a much higher level of preimplantation mortality $\left(\chi^{2}=9.33\right.$, d.f. $\left.=3, P<0.05\right)$. Post-implantation embryonic losses were similar in the three populations.

In all six groups there were no differences in the patterns of intra-uterine losses as they occurred in right and left sides of the reproductive tract (Tables 3 and 4$)$.

The number of implanted embryos exceeded the number of corpora lutea in a very small proportion of females, but in no case was it by more than one, namely, BUB, two cases in fifty-nine females; C57BL, one case in sixty females; $\mathrm{Fb}$ and $\mathrm{Fc}$ one case in sixty-eight females; $\mathrm{A}$, none in twenty-eight females; $\mathrm{I}$, none in forty-eight females; Fi and Fa, two cases in seventy-seven females.

\section{DISCUSSION}

Although the data presented demonstrated that the left and right ovaries of individual mice may produce different numbers of corpora lutea, no differential effects of left and right uterine horns on embryonic viability were evident. The extent of prenatal losses within the uterus appeared to be a function of the total number of potential embryos rather than whether the embryos are in the right or the left uterine horn. This is in agreement with the findings of other workers (Bowman \& Roberts, 1958; McLaren \& Michie, 1959) and suggests that the mouse bicornuate uterus acts as a single unit. McLaren (1963), however, has reported a tendency in mice for the reproductive superiority of the right side in respect of both ovulation rate and of embryonic survival.

Detailed examinations of the differences between right and left ovarian 
activity in non-inbred strains of mice have been made by Falconer, Edwards, Fowler \& Roberts (1961) and McLaren (1963). These workers concluded that the number of eggs or corpora lutea were distributed between sides approximately at random, the variation conforming to a binomial distribution. When the differences in right and left sides conform to a binomial distribution, the ratio of the mean squared difference between sides to the total number of eggs equals unity (cf. Falconer et al., 1961). Values for this ratio that are greater or less than unity show that there is more or less difference between the sides than would be expected if the variations were conforming to a binomial distribution. The present work is the first such examination of ovarian activity in highly inbred strains, and has revealed that in general the two ovaries in these groups are more alike than might be expected. However, in the populations considered, neither the similarities nor the dissimilarity differed to a statistically significant degree from the levels expected if the ovarian variations conformed to the binomial distribution where $P=q=0 \cdot 5$. The $\mathbf{F}_{1}$ and C57BL populations are quite distinct because of the high degree of unidirectional difference between the two ovaries.

The significant negative correlation between the numbers of corpora lutea found in right and left ovaries and the non-significant variations in each ovary's performance both support McLaren's (1963) contention that the ovaries in their sensitivity and activity should be considered as a single unit under normal breeding conditions, and not as individual entities.

The present investigation has shown that differences between populations in both the total number of embryos lost and the manner in which these losses were distributed throughout pregnancy were present. Not only is the number of embryonic deaths characteristic of a given group of isogenetic females, as Krzanowska (1960) has reported, but also the distribution of these deaths throughout gestation is characteristic of the strain. Thus, the importance of population genotype as a control of fertility (MacDowell \& Lord, 1925; Falconer, 1960; Fowler \& Edwards, 1960; Krzanowska, 1960) is confirmed and extended in its scope.

The fact that pre-implantation losses were the greatest contributors to total mortality suggests that the pre-implantation period was one of critical importance in embryonic survival. Such an interpretation is based on the assumptions that the corpora lutea counts represent the actual numbers of eggs shed (Bowman \& Roberts, 1958; Falconer et al., 1961) and that in the mouse almost all eggs are fertilized after mating (Braden, 1957). That these assumptions may not be justified in the $\mathrm{A} / \mathrm{Fn}$ strain is perhaps suggested by the fact that only $54 \%$ of the A/Fn females were pregnant after insemination. It is unfortunate that no data on fertilization rates in females of the A strain appear to be available, for Fainstat (1951) reported that only five of thirty-five inseminated females of his A strain were pregnant. A marked tendency towards infertility in the pre-implantation stages of pregnancy seems a characteristic of this strain, but whether it is due to low fertilization rates, the tendency for 'immediate cleavage' (Braden, 1957) or to embryonic or maternal insufficiencies may only be surmised.

Once implantation had occurred, however, fewer embryos died, and the 
patterns of these deaths were characteristic of each strain of breeding females. In five of the six populations examined and in the $\mathrm{E}$ strain of Krzanowska (1960), a similar marked increase in relative rates of embryonic death between the 8th and 11 th day of gestation has been found. This increased prenatal mortality was not found in BUB females. Embryonic death during gestation may result from the expression of crises either in embryonic development or in the embryo's relationship with the dam. These crises may result from either the segregation of one or more potentially lethal genes or from normal developmental phenomena acting at a particular developmental stage, and appear to be inherited characteristics of the population (Braden, 1959; Noyes, Dickmann, Doyle \& Gates, 1961; Bishop, 1964). Corner (1923) believed that lethal genes could be a major cause of foetal loss, and Lyon (1959) suggested that although some deaths in inbred strains may be due to the segregation of recessive lethals arising by mutation within the strains, such genes are not a major cause of prenatal mortality. Dominant lethals may also cause death at any time, but appear as a general rule to be insignificant in their effects (Bateman, 1958). Probably the best known group of lethals acting at this time during embryogenesis are the alleles at the T locus (Bennett \& Dunn, 1958), but no phenotypic evidence of this allelic series or any other embryonic abnormality was found in embryos of any breeding population.

A normal developmental feature of this period is the growth of the ectoplacenta (Everett, 1935; Snell, 1941) which replaces the yolk sac placenta as the main organ of placentation. This change may cause an embryonic crisis (Huggett \& Pritchard, 1945) but it must also be faced in BUB embryos in which there was no fluctuation in the level of prenatal mortality. That the crisis in the association between the embryo and its dam is under genetic control is suggested by the performance of both $F_{1}$ populations. In the $\mathrm{Fb}$ and $\mathrm{Fc}$ population, embryonic losses at this stage are about half-way between the high losses of the C57BL strain and the low losses in the BUB strain, whereas in the $\mathrm{Fa}+\mathrm{Fi}$ population they are fewer than those of either parent, a performance typical of heterosis. The low level of post-implantation mortality in the BUB strain may best be interpreted as being due, in part, to an inherited enhanced ability to solve the problems of attaining the biplacental state and then replacing it with the definitive chorio-allantoic placenta.

\section{ACKNOWLEDGMENTS}

I am grateful to Dr G. W. Anderson, Professor P. F. Fenton and Professor H. B. Chase for their guidance and stimulus during the course of this project. I also acknowledge with thanks the assistance of Dr A. W. H. Braden and my colleagues who have read and commented on the manuscript.

\section{REFERENCES}

Bateman, A. J. (1958) The partition of dominant lethals in the mouse between unimplanted eggs and deciduomata. Heredity, 12, 467.

Bennett, D. \& Dunn, L. C. (1958) Effect on embryonic development of a group of genetically similar lethal alleles derived from different populations of wild house mice. F. Morph. 103, 135.

Bishop, M. W. H. (1964) Paternal contribution to embryonic death. 7. Reprod. Fert. 7, 383. 
Bowman, J. C. \& Roberts, R. C. (1958) Embryonic mortality in relation to ovulation rate in the house mouse. F. exp. Biol. 35, 138.

BRAden, A. W. H. (1957) Variation between strains in the incidence of various abnormalities in egg maturation and fertilization in the mouse. F. Genet. 55, 476.

Braden, A. W. H. (1959) Are nongenetic defects of the gametes important in the etiology of prenatal mortality? Fert. Steril. 10, 285.

Corner, G. W. (1923) The problem of embryonic pathology in mammals, with observations upon intra-uterine mortality in the pig. Am. F. Anat. 31, 523.

Everetr, J. W. (1935) Morphological and physiological studies of the placenta in the albino rat. 7. exp. Zool. 70, 243.

Fainstat, T. D. (1951) Hereditary differences in ability to conceive following coitus in mice. Science, $114,524$.

Falconer, D. S. (1960) The genetics of litter size in mice. 7. cell. comp. Physiol. 56, Suppl. 1, 153.

Falconer, D. S., Edwards, R. G., Fowler, R. E. \& Roberts, R. C. (1961) Analysis of differences in the number of eggs shed by the two ovaries of mice during natural oestrus or after superovulation. F. Reprod. Fert. 2, 418.

Fowler, R. E. \& Edwards, R. G. (1960) The fertility of mice selected for large or small body size. Genet. Res., Camb. 1, 393.

Grüneberg, H. (1943) The development of some external features in mouse embryos. 7. Hered. 34, 88.

Huggetr, A. St.G. \& Prrtchard, J. J. (1945) Experimental foetal death: the surviving placenta. Proc. R. Soc. Med. 38, 261.

KRAmer, C. Y. (1956) Extension of multiple range test to group means with unequal number of replications. Biometrics, 12, 307.

KRZANOWSKA, H. (1960) Early embryonal mortality in inbred lines of mice and their crosses. Bull. Soc. r. belge gynéc. obst. 30, 719.

Lyon, M. F. (1959) Some evidence concerning the 'mutational load' in inbred strains of mice. Heredity, 13,341 .

MacDowell, E. C. \& Lord, E. M. (1925) The number of corpora lutea in successive mouse pregnancies. Anat. Rec. 31, 131.

McLaren, A. (1963) The distribution of eggs and embryos between sides in the mouse. 7 . Endocr. $27,157$.

McLaren, A. \& Mrchie, D. S. (1959) Superpregnancy in the mouse. 1. Implantation and foetal mortality after induced super-ovulation in females of various ages. F. exp. Biol. 36, 281.

Noyes, R. W., Dickmann, Z., Doyle, L. L. \& Gates, A. H. (1961) Three critical determinants of embryonic development. Proc. IVth int. Congr. Anim. Reprod., The Hague, 3, 593.

Parkes, A. S. (1923) Studies on the sex-ratio and related phenomena. I. Foetal regression in mice. Proc. R. Soc. B, 95, 551.

SNell, G. D. (1941) Biology of the laboratory mouse, p. 40. Blakiston, Philadelphia. 